ISSN 1991- 8690

Website: http://jsci.utq.edu.iq
الترقيم الدولي · 1991 - 199

Email: utjsci@utq.edu.iq

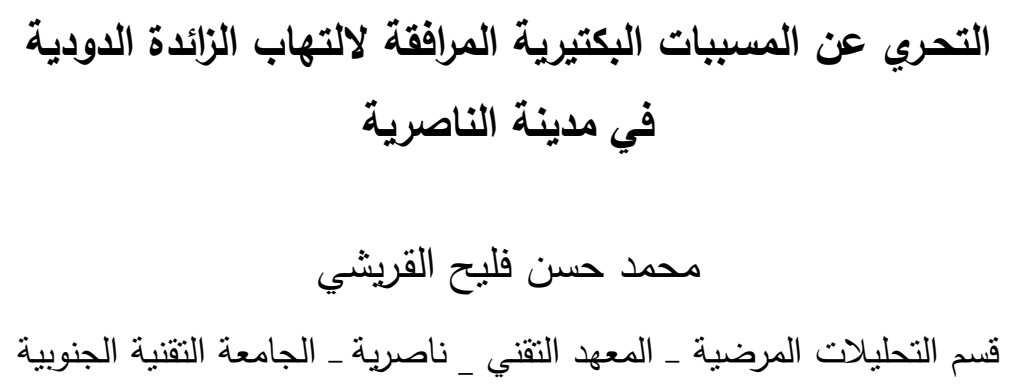

الخلاصة

تضمنت الدراسة الحالية فحص محتوى 100 زائدة دودية مستأصلة جراحيا للتعرف على نوع البكتريا المتواجدة داخل تجويف الزوائد الدودية الملتهبة .

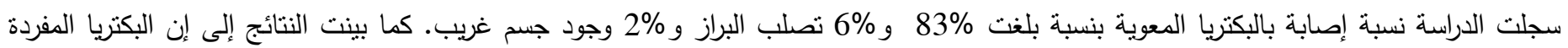

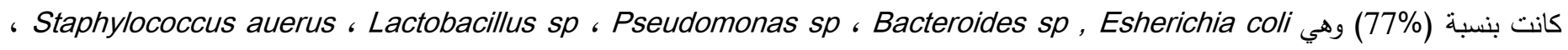
، Yersinia sp ، Klebsiella sp ، Proteus sp ، Salmonella sp

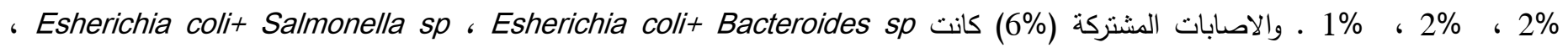
Pseudomonas sp+ Lactobacillus sp الكلمات المفتاحية: الزائدة الدودية ، المسببات البكتيرية ، الاصابة البكتيرية.

\title{
Detection of bacterial agents associated with appendicitis At Al-Nassyria city
}

\author{
Mohammed Hassan Flieh Al-Kurayshi \\ Department of Medical Laboratory - Al-Nasiriya Technical Institute - Southern Technical University \\ E-mail: m-alkutayshi@yahoo.com
}

\section{Summary}

The present study was include examination of the content of 100 surgical removed appendices for identify the bacteria found in flamed appendix cavity. The study recorded infection percentage by intestinal bacteria reached $83 \%$, fecalith $6 \%$ and body foreign $2 \%$. The results showed that the single infection percentage was $77 \%$ included infection of Esherichia coli, Bacteroides sp, Pseudomonas sp, Lactobacillus sp, Staphylococcus auerus, Salmonella sp, Proteus sp, Klebsiella sp and Yersinia sp by percentages (33\%, 15\%, 11\%, 7\%. 4\%, 2\%, 2\%, 2\%, 1\%) respectively. Dual infection percentage (6\%) included infection of Esherichia coli+ Bacteroides sp, Esherichia coli+ Salmonella sp, Pseudomonas $s p+$ Lactobacillus $s p$ by percentages were $(3 \%, 2 \%, 1 \%)$ respectively.

Keywords: Appendix, Bacterial Pathogens, Bacterial infection. 


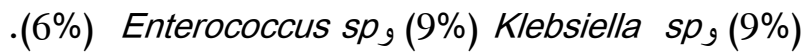
قام AL Salami (2006) بفص و 110 زائدة دودية ملتهبة وسجل

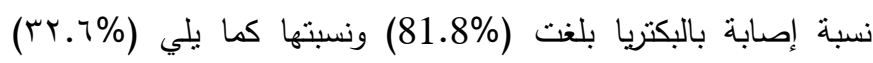
(1).r\%) Bacteroides spp (1).9\%) Esherichia coli Pseudomones $\quad(9.9 \%)$, Klebsiella pneumoniae , Citrobacter freundii (6.3\%) , aeruginose (3.6\%) , Proteus mirablis, Salmonella typhi Peptostreptococus (1.8\%) , Enterobacter aerogenes , Staphylococcus aureus spp

\section{- Clostridium perfringes}

أنثارت الخالدي (2007) عند فحصها 110 زائدة دودية في مدينة الديوانية إلى إن نسبة الإصابة بالبكتريا المعوية كانت $57.28 \%$

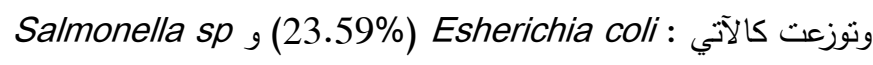
$(7.86 \%)$ Yersinia $s p$ و (8.98\%) Shigella $s p$ و (13.48\%) - (3.37\%) Proteus sp,

تهدف الدراسة للتعرف على انواع المسبيات البكتيرية المرافقة لالتهاب الزائدة الدودية والتي قد تكون سبياً في التهابها.

\section{المواد وطرائق العمل}

\section{1. جمع العينات Collection of samples}

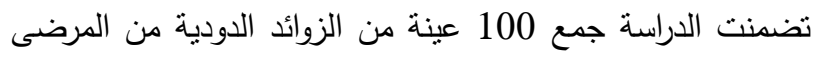

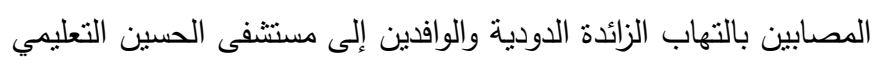
في محافظة ذي قار للمدة من شهر تموز 2013 ولغاية شهر حزيران

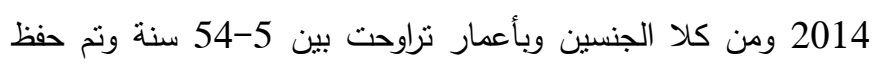

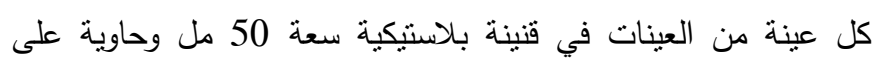

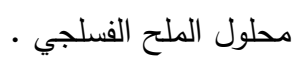

2. فحص العينات Examination of samples فحصت العينات بوضعها في طبق بتري ثم عمل شق طولي بواسطة

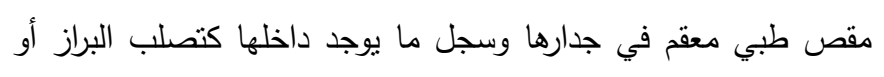
وجود جسم غريب

3.

تم استعمال مسحات قطنية معقمة حيت مسحت هذه المسحات

داخل عينة الزائدة الدودية بعد فتحها طوليا وبظروف معقمة بعدها
الزائدة الدودية Vermiform appendix هي نركيب يشبه

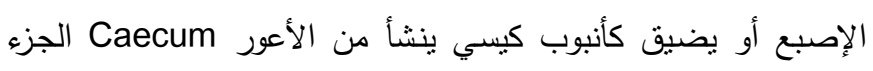

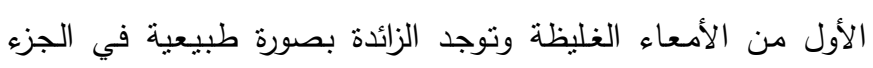

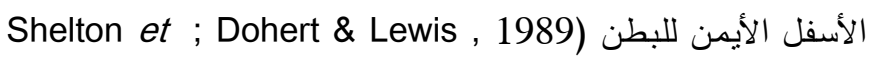

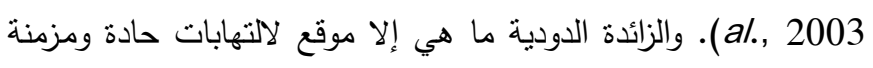

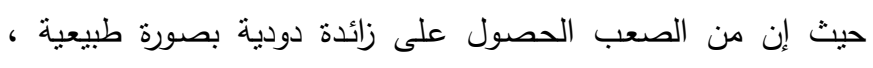

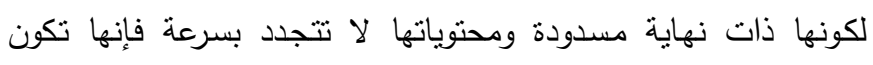

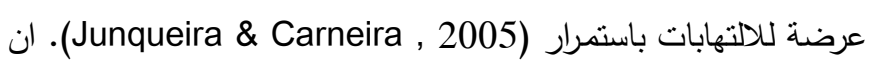

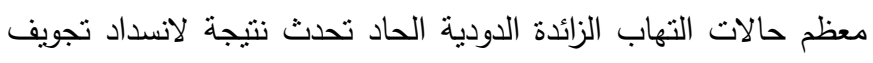

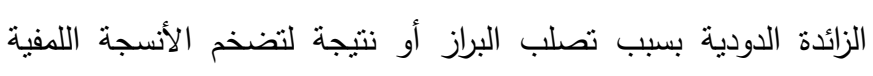

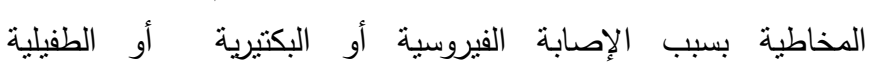

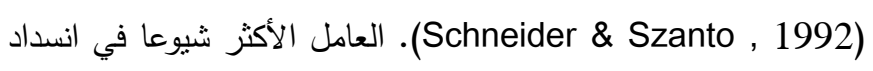

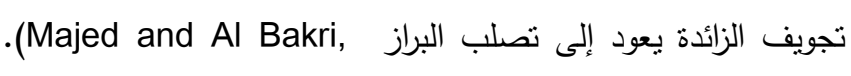

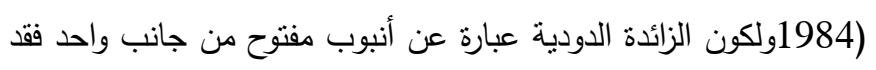

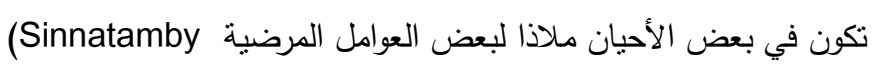
(1999 ,. لقد أكدت البحوث والدراسات الأخيرة دور كل من البكتيريا

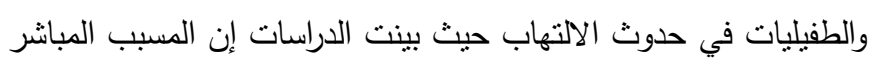

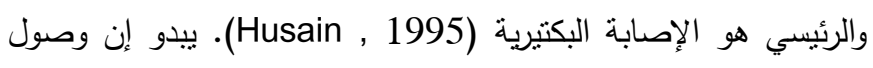

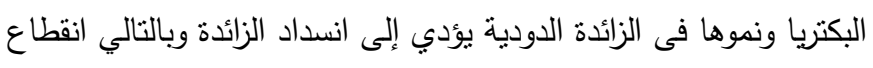

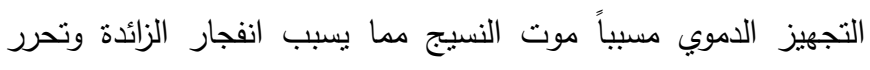

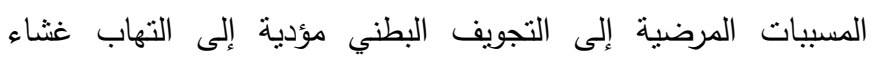

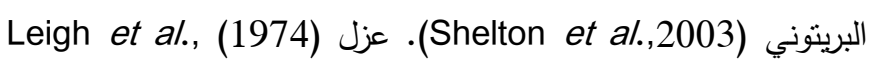
29\% بنسبة إصابة بلغت Bacteroides spp Klebsiella, بنسبة 27\% عند فحصه لمجموعة من الزوائد الدودية الستأصلة جراحيا. سجل Okoro (1998) نسبة إصابة بيكتريا Yersinia enterocolitica المفحوصة. توصل الباحثان Bennion \& Baron (1990) بعد فحص فلروان

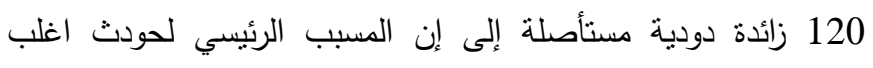

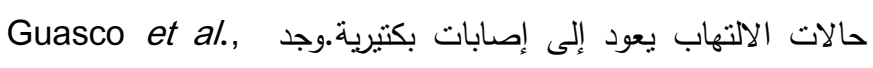
(1991) بأن 45 زائدة دودية موجبة للفحص البكتيري بنسبة بلغت الفيات

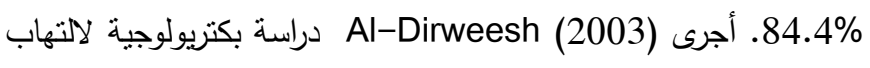

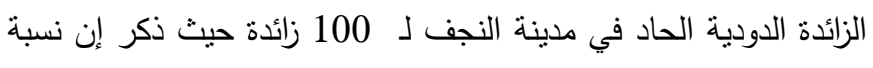
Bacteroides كانت (53\%) الإصابة ببكتريا Esherichia coli Lactobacillus sp , (23\%) Pseudomones sp, (33\%) spp 
غالبا بسبب نصلب البراز أو وجود جسم غريب أو بسبب الديدان الاسطوانية أو الخيطية ونادرا ما يكون بسبب وجود ورم في التجويف. جدول (1) نوع وعدد الإصابة في تجويف الزوائد الدودية المستأصلة

\begin{tabular}{|c|c|c|c|c|}
\hline 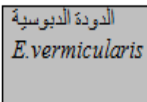 & $\begin{array}{l}\text { جسم غريب } \\
\text { body } \\
\text { foreign }\end{array}$ & $\begin{array}{l}\text { الإصابة النكتبرية } \\
\text { Bacterial } \\
\text { infection }\end{array}$ & $\begin{array}{c}\text { Fُملبَ البِراز } \\
\text { Fecalith }\end{array}$ & نوع الإحسابة الموجودذ \\
\hline 9 & 2 & 83 & 6 & عدد الإصنابات \\
\hline
\end{tabular}

$\mathrm{X}^{2}$ Cal.: $180.4, \mathrm{X}^{2}$ tab. 7.81, P: 0.00

أما جدول (2) وجدول (3) فيبينان الإصابات البكتيرية المفردة والثنائية

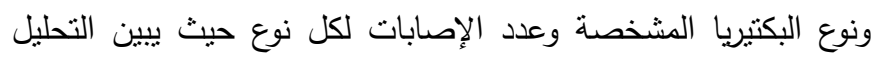

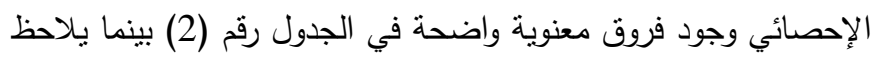
عدم وجود فروق معنوية في الجدول (3) ـ أثنارت النتائج إلى أن بكتريا كsherichia coli الإصابات البكتبرية قريبة نوعا ما لما ذكره (2006) AL Salami واقل لإنل مما ذكره Al-Dirweesh (2003) وقد يعزى السبب في تفاوت نسب الإصابة إلى كون البكتريا المعزولة هي موجودة بصورة طبيعية في لادي

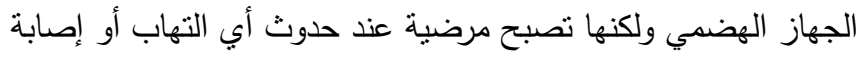
جدول (2) يوضح الإصابة المفردة للبكتريا المعوية في الزوائد المستأصلة

\begin{tabular}{|c|c|c|}
\hline الآنسبة المئوية للإصابة \% & عدد الإصابات & البكتريا \\
\hline 39.76 & 33 & Esherichia coli \\
\hline 18.07 & 15 & Bacteroides fragilis \\
\hline 13.25 & 11 & Pseudomonas aeroginusa \\
\hline 8.43 & 7 & Lactobacillus spp \\
\hline 4.82 & 4 & Staphylococcus auerus \\
\hline 2.41 & 2 & Salmonella typhi \\
\hline 2.41 & 2 & Proteus mirabilis \\
\hline 2.41 & 2 & Klebsiella pneumoniae \\
\hline 1.21 & 1 & Yersinia enterocolitica \\
\hline 92.77 & 77 & 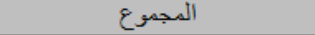 \\
\hline
\end{tabular}

$\mathrm{X}^{2}$ Cal.: $79.7, \mathrm{X}^{2}$ tab.:15.51, P: 0.00

جدول (3) يوضـح الإصابة المشنركة للبكتريا المعوية في الزوائد المستأصلة

\begin{tabular}{|c|c|c|}
\hline الآنسبة المئوية للجصابة \% & عدد الإصابات & البكتربيا \\
\hline 3.62 & 3 & $\begin{array}{l}\text { Esherichia coli+ Bacteroides } \\
\text { fragilis }\end{array}$ \\
\hline 2.41 & 2 & $\begin{array}{c}\text { Esherichia coli+ Salmonella } \\
\text { typhi }\end{array}$ \\
\hline 1.21 & 1 & $\begin{array}{c}\text { Pseudomonas aeroginusa }+ \\
\text { Bacteroides fragilis }\end{array}$ \\
\hline 7.23 & 6 & الدجموع \\
\hline
\end{tabular}

سجلت الدراسة الحالية اصابة البكتيريا في الزوائد المفحوصة بنسبة بلغت

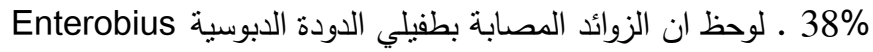
vermicularis
خططت هذه المسحات على الأوساط الزرعية الخاصة بالبكتريا (Blood agar , Nutrient agar , MacConky agar, kanamycinvancomycin blood agar (KvA) and Neomycin blood (agar (NBA). ثم نقلت إلى الحاضنة بدرجة حرارة 37 م وحضنت لمدة 24- 48 ساعة ، شخصت البكتريا حسب الصفات المظهرية

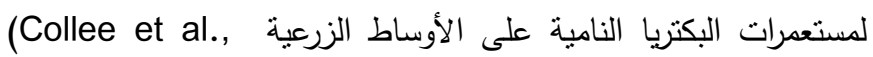
(1996 وكذلك حسب شكل وتصبيغ البكتيريا والاختبارات الكيموحيوية

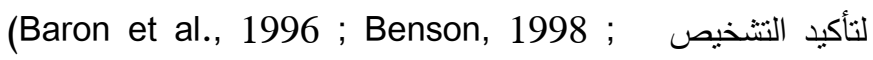
Brook et al,. 1998)

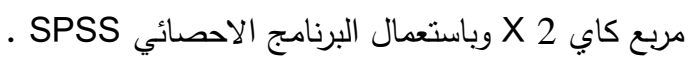

\section{النتائحج والمناقشية}

أظهرت نتائج الدراسة الحالية التي شملت فحص محتوى 100 زائدة دودية مزاله جراحيا إلى إن عدد الذكور الدصابين بالتهاب الزائدة الدودية

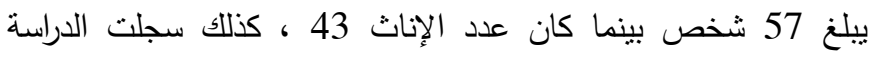

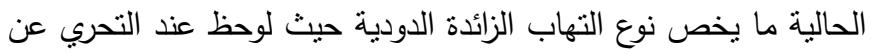

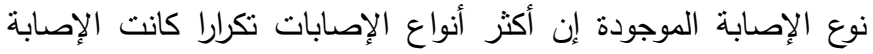
البكتيرية واقلها وجود الجسم الغريب كما مبين في جدول (1) وعند إجراء التحليل الإحصائي للنتائج لوحظ وجود فروق معنوية عند مسنوى احتمالية 6\% حيث سجلت الدراسة الحالية حالة تصلب البراز بنسبة Pي 0.05 وهذه النتيجة نختلف عما توصل إليه Al-Dirweesh (2003) حيث Mowlavi et al. سجل نسبة بلغت 46\% لحالة تصلب البراز و و (2004) سجل نسبة 45\% وقد يعود السبب إلى حجم العينة الددروسة

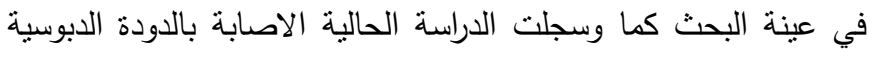

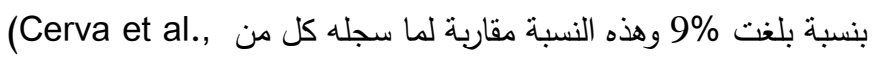
1991; Al-Dabbagh et al., 1994; Al-Mosa, 2002; Dawood et al., 2007) النتائج إلى إن نسبة الإصابة كانت 83\% وهي أعلى من نسبة الإصابة 57.28\% التي ذكرتها الخالدي (2007) وكانت نسبة الإصابة المسجلة قريبة لما توصل إليه (1994) Jindal \& Kaur في الهند حيث سجلا نسبة إصابة بالبكتريا المعوية بلغت 85\% بعد فحصهما 105 زائدة دودية وقريبة نوعا ما لما سجله Dawood et al. (2006) في مدينة الديوانية حيث بلغت نسبة الإصابة البكتيرية 75\% عند فحصه لمحتوى

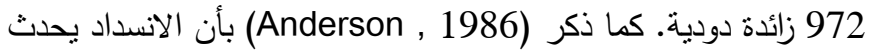


Bennion, R.S. \& Baron, E.J. (1990). The bacteriology of gangrenous \& perforated appendicitis revisited. Depart. of surgery olive view, Med. Center, Los Angeles Califonia.

Benson, H.J.(1998).Microbiology Application Laboratory Manual of Medical information.2ed, Merck and Co., Inc.

Brook, I., P. Yo Cum and K. Shah. (1998). Aerobic and anaerobic bacteriology of otorrhea asso ciated with tympano stomy tubes in children. Acta. Otolaryngol. 118: 206-210.

Cerva, L.; Schrottenbaum, M. \& Kilment, V. (1991). Intestinal parasites : a study of human appendicitis. Folia-parasitolog., 38 (1):5-9. (Medline Abst.).

Collee, J. G. ; Fraser, A. G. ; Marmion, B. P. \& Simmon, A. S. (1996). Practical medical microbiology. Chunchill Living Stone.

Dawood, K. A.; Al-Khafagy, H. \& Al-Umiashi, B. (2006). Study of appendicitis in Diwania. J. Vet. Med. Qadisiya, 5(2): 78-80.

Dohert, G. M. \& Lewis, F. R. (1989). Appendicitis continuing challenge. In: AL Salami, F. K. K. (2006). Bacteriological study regarding acute appendicitis. M. Sc. Thesis, Coll. Med. Univ. Babylon, PP: 91.

Efraimidou, E.; Gatopoulou, A.; Stamos, C.; Lirantzopoulos, N. \& Kouklakis, G. (2008). Enterobius Vermicularis infection of the appendix as a cause of acute appendicitis in a Greek adolescent: a case report. Cas. J., 1(1): 376.

Guasco, C.; Roncheto, F.; Milani, P.; stocchini. E. \& Pistono, P. G. (1991). Bacteriology of abdominal pus in 43 cases of acute appendicitis and appendicle abscess at the IvraCastellamonate Hospital: isolation of aerobic

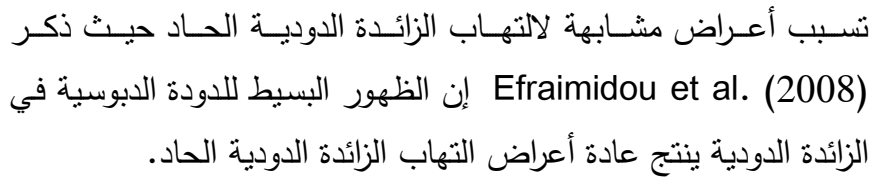

\section{References}
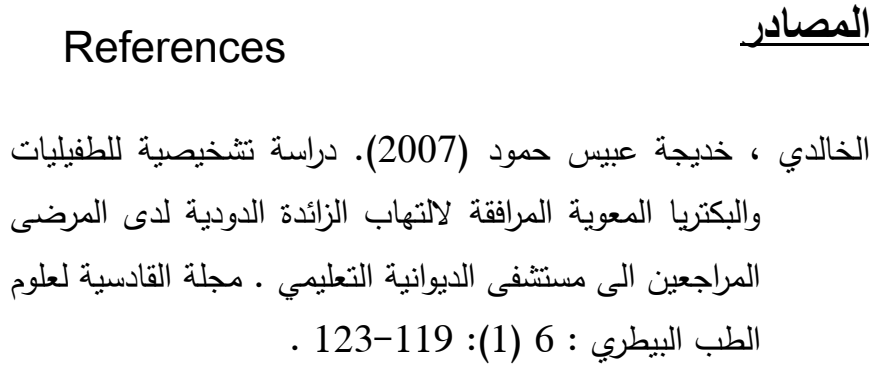

Al-Dabbagh, N. Y.; Al-Izzi, N. S. \& Hayatte, Z. G. (1994). The role of Enterobius vermicularis in human appendicitis. J. Fac. Med. Baghdad, 36(3): 465-473.

Al-Dirweesh, H. M. A. (2003). Bacteriological \& histopathological study of acute appendicitis in Al-Najaf teaching hospital. M.B.CH.B. Thesis. Coll. Med. Univ. Kufa. PP: 35.

Al-Mosa, A. H. (2002). Epidemiological study of some parasitic causes for some digestive tract disorders of humans in Al-Hilla city. M. Sc. Thesis, Coll. Med. Univ. Kufa, PP: 92.

Al-Salami, F. K. K. (2006). Bacteriological study regarding acute appendicitis. M. Sc. Thesis, Coll. Med. Univ. Babylon, PP: 91.

Anderson, J. R. (1986). Muir's textbook of pathology. In: Okolie, B. I.; Okonko, I. O.; Ogun, A. A.; Adedeji, A. O.; Donbraye, E.; Nkang, A. O.; Iheakanwa, C. I.; \& Onwuchekwa, E. C. (2008). Incidence and Detection of Parasite Ova in Appendix from Patients with Appendicitis in South-eastern, Nigeria. World J. Agricul. Sci., 4: 795-802.

Baron, E.J.,L.R. Peterson and S.M. Finegold.(1996). Bailey and Scott's, Diagnostic microbiology.9th ed, C.V. Mosby Company. 
appendicitis. Iranian. J. Publ. Health., 33(3): 27-31.

Okoro, I. (1998). The role of Yersina enterocolitica is appendicitis in Zaria. East Afr. Med. J. 65(9):625.

Schneider, A. S. \& Szanto, A. A. (1992). Pathology board review Williams \& wilkins a waverly comp. Philadelphia, PP: 220-223.

Shelton, T.; Lefering, R. \& Schwartz, R. W. (2003). Acute appendicitis current diagnosis and treatment . In: Al-Salami, F. K. K. (2006). Bacteriological study regarding acute appendicitis. M. Sc. Thesis, Coll. Med. Univ. Babylon, PP: 91.

Sinnatamby, C. S. (1999). Last's Anatomy. Churchill Livingstone, PP: 521. and anaerobic bacteria and drug sensitivity. J. Bacteriol Virol- Immunol. 84 (1-12):77.

Husain, M.H. (1995). Microbial causative agents of appendicitis. M. Sc. Thesis, Coll. Med. Univ. Baghdad, PP: 77.

Jindal, N. \& Kaur, G. D. (1994). Bacteriology of acute appendicitis with special reference to anaerobics. Coll. Med. Amirtsar, India.

Junqueira, L.C. \& Carneira, J. (2005). Basic histology: text and atlas. 11th ed. McGraw-Hill, USA, PP: 502 .

Leigh, D. A.; Simmons, K. \& Norman, E. (1974). Bacterial flora of the appendix fosse in appendicitis and post operative wound infection. J. Clin. Path. 27:997.

Majeed, A. \& Al-Bakri, H. (1984). Acute appendicitis in Nineva province. J. Fac. Med. Baghdad, 26(1): 71-76.

Mowlavi, G. h.; Massoud, J.; Mobedi, I.; Rezaian, M.; Mohammadi, S. S.; Mostoufi, N. E. \& Gharaguzlo, M. J. (2004). Enterobius vermicularis: A controversial cause of 